\title{
O Segredo do Estudante de Medicina, a Sua Vinculação ao Dever de Sigilo e o Direito em Aceder e Reutilizar Informação de Saúde
}

\section{Medical Student Secrecy, its Link to the Duty of Confidentiality and the Right to Access and Reuse Health Information}

Rui GUIMARÃES $\square^{1,2,3}$, Miguel GUIMARÃES ${ }^{2,4}$, Nuno SOUSA ${ }^{5,6}$, Amélia FERREIRA $^{3,7,8}$

Acta Med Port 2019 Jan;32(1):11-13 - https://doi.org/10.20344/amp.10958

\section{RESUMO}

Os autores abordam o vazio legal que existe, no acesso, por parte de estudantes de medicina, aos registos clínicos, à informação de saúde, na posse e à guarda legal e institucional das unidades de saúde. Por outro lado, desenvolvem uma tese jurídica que configura a criação do segredo do estudante de medicina e a sua vinculação ao dever de sigilo, como pressupostos que fundamentam o direito do estudante de medicina em aceder e reutilizar informação de saúde. O estudante de medicina tem legitimidade para aceder a informação de saúde, a registos clínicos, já que é inequívoco ser portador de uma necessidade informacional, legítima, constitucionalmente protegida e suficientemente relevante. Concluem, que o poder legislativo se associe às instituições, universitárias e hospitalares, instituindo, por diploma legal, o Segredo do Estudante de Medicina, a sua vinculação ao dever de sigilo e o direito do estudante de medicina em aceder e reutilizar informação de saúde. E deve fazê-lo, em diploma específico, nos precisos termos do texto aprovado, por unanimidade, pelo Conselho das Escolas Médicas Portuguesas, pelo Conselho Nacional de Ética e Deontologia Médicas, pelo Conselho Nacional da Ordem dos Médicos e pelo Bastonário da referida Ordem.

Palavras-chave: Acesso à Informação/legislação e jurisprudência; Educação de Graduação em Medicina; Estudantes de Medicina; Portugal; Registos Electrónicos de Saúde; Registos Médicos; Sigilo

\section{ABSTRACT}

The authors address the legal void that exists regarding medical student access to clinical records and health information that local healthcare organizations hold under legal and institutional custody. They develop a legal thesis that configures the creation of medical student professional secrecy and its connection with the duty of confidentiality as assumptions that underlie the medical student's right to access and reuse health information. Medical students have the legitimacy to access health information and clinical records, as they bear an unequivocal informational, legitimate, constitutionally protected and sufficiently relevant need. They conclude that the legislature must work together with universities and hospital institutions to legally establish the concept of Medical Student Professional Secrecy, its link to the duty of confidentiality and the right of the medical student to access and reuse health information. Furthermore, it must do so in a specific legal act and in the precise terms of the text approved unanimously by the Council of Portuguese Medical Schools, by the National Council of Medical Ethics and Deontology, by the National Council of the Portuguese Medical Association and by its President.

Keywords: Access to Information/legislation \& jurisprudence; Confidentiality; Education, Medical, Undergraduate; Electronic Health Records; Medical Records; Portugal; Students, Medical

O acesso por parte de estudantes de medicina a informação de saúde, a registos clínicos, na posse e à guarda legal e institucional das unidades de saúde, é uma necessidade óbvia que decorre intrinsecamente da sua condição de estudantes de medicina e cuja prática é tão antiga quanto o ensino da medicina; o que mudou, foi o Mundo, e com ele o Direito.

Muitos advogam, sobretudo nos Estados Unidos da América, que esta questão do acesso por parte de estudantes de medicina aos registos clínicos, surge com o advento da informática. ${ }^{1}$ Nada de mais errado. A questão do acesso por parte de estudantes de medicina aos registos clínicos dos doentes não é uma questão informática. É uma questão jurídica. O que se trata, é de sabermos se o estudante, por ser estudante de medicina, tem ou não legitimidade para aceder a registos clínicos, independentemente do suporte onde esses registos residem ser papel ou digital. A questão de fundo, não é dar logins e passwords. A questão de fundo é sabermos se o nosso ordenamento jurídico tem (ou não), fundamentos que suportem e legitimem que a qualidade de se ser estudante de medicina é condição, qualidade, e função suficiente para enquadrar o acesso como um ato

\footnotetext{
1. MEDCIDS - Department of Community Medicine, Health Information and Decision. Faculty of Medicine. University of Porto. Porto. Portugal.

2. Departament of Urology. University Hospital Center of São João. Porto. Portugal.

3. CISPFEM - Department of Public Health and Forensic Sciences and Medical Education. Faculty of Medicine. University of Porto. Porto. Portugal.

4. President. Portuguese Medical Association. Lisbon. Portugal.

5. President. School of Medicine. University of Minho. Braga. Portugal.

6. Director. Clinical Academic Center (2CA). Braga. Portugal.

7. Dean. Faculty of Medicine. University of Porto. Porto. Portugal.

8. Coordinator. Council of Portuguese Medical Schools. Porto. Portugal.

$\triangle$ Autor correspondente: Rui Guimarães. ruiguimaraes@med.up.pt

Recebido: 18 de junho de 2018 - Aceite: 30 de outubro de 2018 | Copyright @ Ordem dos Médicos 2019
} 
legítimo, constitucionalmente protegido e suficientemente relevante, após ponderação no quadro do princípio da proporcionalidade e de todos os direitos fundamentais em presença. $^{2}$

A visão instrumental que tem dominado este tema, colocando a tónica no plano da informática, limita a abordagem e desvia-nos das que são as verdadeiras questões:

Como compatibilizar o direito à privacidade, ao sigilo e à confidencialidade de um doente, com a necessidade de um estudante de medicina ter acesso a registos clínicos como condição indispensável e inultrapassável à sua formação? Como compatibilizar o direito à privacidade, ao sigilo, e à confidencialidade de um doente com o direito de ser estudante de medicina e com o direito de ensinar medicina?

Estamos a falar de direitos. E de Direito. Dos direitos dos doentes, do direito de aprender, do direito de ensinar e do direito de avaliar. Do direito de (re)utilizar registos clínicos para fins educativos ou de investigação e desenvolvimento. Isto tudo converge para o superior interesse, que é o de ensinar estudantes para que um dia venham a ser médicos. Isto é uma equação em que todos beneficiam e uma previsão estatuída na lei.

A condição de estudante de medicina é uma condição específica, peculiar e distinta, com necessidades informacionais específicas, legitimadas pelo direito de adquirirem conhecimentos clínicos e científicos inerentes à sua condição e qualidade de estudantes de medicina, cuja função é, fundamentalmente, estudarem as ciências biomédicas e estabelecer a sua interface com as ciências clínicas. ${ }^{3}$ Essa aprendizagem faz-se por diferentes e variadas formas, sendo certo que o contacto com a intimidade dos doentes, não apenas é necessária, mas mais do que necessária, é imprescindível.

O ensino da medicina é um ensino diferente. O estudante de medicina é, assim, um estudante necessariamente diferente. $O$ dever de sigilo que o vai acompanhar pela vida fora não tem início no seu primeiro dia como médico. Tem início no primeiro dia em que, enquanto estudante, contacta com um doente. Acresce que o dever de sigilo do médico não é maior nem menor que o dever de sigilo do estudante de medicina. De igual modo, não é menor ou maior o direito à confidencialidade do doente, relativamente ao estudante ou ao médico. Há sim, um mesmo dever de sigilo. Há sim, um mesmo direito à confidencialidade. $E$ isto porque há apenas um direito à privacidade, constitucionalmente protegido, que obviamente não se altera, aumentando ou diminuindo o volume, em razão da qualidade de quem entra na esfera jurídica de outrem.

$\mathrm{Na}$ verdade, há que reconhecer de forma expressa, pública e estatutária, o segredo do estudante de medicina como precursor do segredo médico. Ambos constituem segredos e estão destinados a garantir a privacidade dos doentes, como as duas faces de uma moeda: de um lado, prima facie o direito à confidencialidade; do outro, o dever de sigilo. O segredo médico, tem, pois, um precursor, que é o segredo do estudante de medicina, e isto apresenta uma lógica e uma cronologia factual óbvias. Uma precede a ou- tra. Têm os mesmos fundamentos jurídicos, porque visam a proteção do mesmo bem jurídico: a privacidade. Nenhum outro estudante, porque nenhuma outra profissão entra de tal forma na intimidade do Ser Humano, como o estudante de medicina, cuja aprendizagem - onde também o contacto com os doentes é fundamental - fará dele um médico. ${ }^{4}$ Nesse período de aquisição de conhecimentos, sobretudo a partir do momento em que o estudante de medicina inicia o contacto pessoal e direto com os doentes, a aprendizagem passa também pelo acesso aos registos clínicos dos doentes, condição indispensável e inultrapassável do processo de aprendizagem. ${ }^{5}$

Acresce que a privacidade é um bem jurídico com proteção constitucional, quer entre nós, quer em todos os ordenamentos jurídicos dos Estados-Membros da União Europeia, quer ainda, em documentos magnos do Parlamento Europeu e do Conselho, onde a privacidade do Ser Humano está numa escala que só tem um bem que lhe é superior: o valor vida do Ser Humano. Aliás, a privacidade é um bem jurídico colhido noutras latitudes jurídicas e geográficas fora da família romano-germânica dominante no espaço europeu, como é o caso dos Estados Unidos da América.

Todavia, a forma como tais acessos se têm vindo a concretizar, sem o pertinente e necessário enquadramento legal, mereceu por parte do Conselho das Escolas Médicas Portuguesas uma reflexão intelectualmente séria, abrangente, temperada pelo bom senso, e juridicamente assente no direito positivo, na doutrina e na jurisprudência (Apêndice 1: https://www.actamedicaportuguesa.com/revista/index.php/amp/article/view/10958/Apendice_01.pdf).

Dessa reflexão foi possível concluir que a primeiríssima consideração que o acesso por parte de estudantes de medicina a informação de saúde, a registos clínicos, na posse e à guarda legal e institucional das unidades do sistema de saúde, nos merece, é que a substância da questão é eminentemente jurídica, isto é, trata-se de sabermos se há - e no caso de haver, qual é - o fundamento da legitimidade jurídica de um estudante de medicina para aceder a um registo clínico (Parte I do Apêndice 2: https://www. actamedicaportuguesa.com/revista/index.php/amp/article/ view/10958/Apendice_02.pdf).

O estudante de medicina, nesse âmbito, qualidade, e funções, de tudo o que ouvir, presenciar ou tiver acesso, direto ou indireto, e que se relacione com informação de saúde, com registos clínicos, independentemente da pessoa estar viva ou já ter falecido, em nome da sua honra de estudante de medicina, e do direito à confidencialidade, à privacidade e ao sigilo dos doentes, de tudo guardará segredo, assumindo o segredo do estudante de medicina como um segredo precursor do segredo médico que o futuro lhe reserva, ocorrendo a sua vinculação jurídica ao dever de sigilo, na exata medida e termos que o segredo médico vincula o médico (Cf. Parte II do do Apêndice 2: https:// www.actamedicaportuguesa.com/revista/index.php/amp/ article/view/10958/Apendice_02.pdf).

O direito de acesso e (re)utilização da informação de 
saúde por estudantes de medicina e a legitimidade que consente e fundamenta o acesso de um estudante de medicina a registos clínicos, a informação de saúde, na posse e à guarda legal e institucional das unidades de saúde, ocorre, imperativamente, no quadro da lei do acesso e (re)utilização (Cf. Parte III do do Apêndice 2: https://www. actamedicaportuguesa.com/revista/index.php/amp/article/ view/10958/Apendice_02.pdf), no respeito absoluto pelos direitos das pessoas singulares, e tem um duplo fundamento:

Por um lado, num interesse pessoal, direto, legítimo, constitucionalmente protegido e suficientemente relevante, no quadro do princípio da proporcionalidade e de todos os direitos fundamentais em presença; e é pessoal e direto, porque tem impacto imediato na esfera jurídica do estudante de medicina.

Por outro, a legitimidade também encontra fundamento num interesse em função da sua qualidade de estudante de medicina, que se traduz no cumprimento de incumbências académicas indispensáveis à sua formação universitária. Esse interesse está, por conseguinte, justificado pelo exercício da sua qualidade e função de estudante: a informação é necessária em razão do desempenho daquelas funções, para esse desempenho, e por causa desse desempenho.

O estudante de medicina tem, assim, legitimidade para aceder a informação de saúde e a registos clínicos na posse e à guarda das unidades de saúde, já que é inequívoco ser portador de uma necessidade informacional legítima, constitucionalmente protegida, e suficientemente relevante. Todavia, trata-se de uma necessidade vinculada, quer ao princípio da proporcionalidade, quer a todos os direitos fundamentais em presença máxime aos direitos das pessoas singulares, sendo a confidencialidade garantida pela vinculação jurídica do estudante ao dever de sigilo, em consequência do seu segredo de estudante de medicina.

\section{CONCLUSÃO}

É urgente acabar com um vazio legal e pernicioso, porque é indutor de práticas não apoiadas em princípios legais. O Conselho das Escolas Médicas Portuguesas tomou a iniciativa, equacionou questões e apresentou soluções, no que é acompanhado pelo Bastonário da Ordem dos Médicos, pelo Conselho Nacional de Ética e Deontologia Médicas, e pelo Conselho Nacional da Ordem dos Médicos (Apêndice 1: https://www.actamedicaportuguesa. com/revista/index.php/amp/article/view/10958/Apendice_01.pdf).

$\mathrm{Na}$ verdade, é imperativo prosseguir com as novas referências na formação dos futuros médicos, (Cf. Parte IV do do Apêndice 2: https://www.actamedicaportuguesa.com/revista/index.php/amp/article/view/10958/Apendice_02.pdf) um novo tempo marcado por um paradigma de uma cultura de responsabilização dos estudantes e das instituições, com novas competências - transversais e transformadoras - na educação e formação médica dos estudantes de medicina, futuros profissionais.

Com a criação do segredo do estudante de medicina através da sua vinculação jurídica ao dever de sigilo, momento inédito, promissor, pedagógico e prévio ao segredo médico de que virão a ser titulares, estão criados os pressupostos que fundamentam e legitimam o acesso por parte dos estudantes de medicina aos registos clínicos na posse e à guarda legal e institucional das unidades de saúde.

\section{Propostas}

1. As instituições, quer hospitalares quer universitárias, devem criar condições, estabelecendo protocolos, para que o direito ocupe o seu espaço, regulando o acesso e (re) utilização dos estudantes de medicina aos registos clínicos, no quadro da Lei 26/2016, de 22 de agosto.

2. O poder legislativo, alicerçado numa ética da Res Publica, deve associar-se às instituições universitárias e hospitalares, instituindo, por diploma legal (Cf. Parte $V$ do do Apêndice 2: https://www.actamedicaportuguesa.com/revista/index.php/amp/article/view/10958/Apendice_02.pdf), o segredo do estudante de medicina, a sua vinculação ao dever de sigilo e o direito do estudante de medicina em aceder e (re)utilizar informação de saúde.

\section{REFERÊNCIAS}

1. Welcher CM, Hersh W, Takesue B, Stagg Elliott V, Hawkins RE. Barriers to medical students' electronic health record access can impede their preparedness for practice. Acad Med. 2018;93:48-53.

2. Assembleia da República. Decreto Lei $n^{\circ}$ 26/2016, 22 de agosto, que aprova o regime de acesso à informação administrativa e de reutilização dos documentos administrativos. Diário da República. $1^{a}$ série. 2016;2777-8.

3. McGowan JJ, Passiment M, Hoffman HM. Educating medical students

as competent users of health information technologies: the MSOP data. Stud Health Technol Inform. 2007;129:1414-8.

4. Wittels K, Wallenstein J, Patwari R, Patel S. Medical student documentation in the electronic medical record: patterns of use and barriers. West J Emerg Med. 2017;18:133-6.

5. Tierney MJ, Pageler NM, Kahana M, Pantaleoni JL, Longhurst CA Medical education in the electronic medical record (EMR) era: Benefits, challenges, and future directions. Acad Med. 2013;88:748-52. 